\title{
Environmental equity as a criterion for water management
}

\author{
MARIA GRANDE ${ }^{1,2}$, CARLOS GALVÃO ${ }^{2}$, LÍVIA MIRANDA ${ }^{2}$ \& IANA RUFINO2 \\ 1 Instituto Federal da Bahia, Av. Universitária s/no, Simões Filho BA, 43700-000, Brazil \\ mhdgrande@gmail.com \\ 2 Universidade Federal de Campina Grande, R. Aprígio Veloso 882, Campina Grande PB, 58429-900, Brazil
}

\begin{abstract}
Environmental equity is a concept derived from the (un)equal exposure to environmental degradation by different social groups, usually minorities and low-income people exposed to major environmental risks, also known as environmental justice. It is assumed that no group of people, independent of race, ethnicity or socioeconomic class, should support, either in concentrated or unevenly distributed form, the negative environmental impacts resulting from industrial, agricultural, commercial and infrastructure activities or government programs and policies. In this paper the concept of environmental equity is explored as a criterion for water management through the analysis of a typical coupled human-natural system: the Epitácio Pessoa Reservoir, located in the semi-arid region of Brazil. Inefficient water resource management has caused unequal access to water by the population, particularly during drought periods. However, census data indicate that population have practically the same access to water, which actually is not able to reflect the actual picture. This study argues that environmental equity can be an additional criterion to improve water management.
\end{abstract}

Key words environmental equity; water access; water-related environmental injustice; water management

\section{INTRODUCTION}

Environmental equity is an issue that burst out in the 1990s in the USA. At that time, it was directly related with minorities and low-income populations, exposed to disproportional environmental risks when compared to white or middle and high-income populations. For this reason the terms "environmental justice" and "environmental racism" have been used (Holifield 2001). According to the Environmental Protection Agency of the USA - EPA (n.d.), "Environmental Justice is the fair treatment and meaningful involvement of all people regardless of race, colour, national origin, or income with respect to the development, implementation, and enforcement of environmental laws, regulations, and policies". Historically, the protest movement for environmental equity was led essentially by local organizations dissatisfied with the establishment of polluted and hazardous activities in their neighbourhoods (Carr 1996).

The methodology used in the earlier environmental equity analysis compared census data arranged by zip codes or city blocks. Later studies began to use risk assessment methodology and attempted to measure the risk of living near an industrial facility considering different categories of hazards and health and safety risks associated with the nearby community (Carr 1996). More recently, GIS technology has been shown to be a suitable tool for this type of research, especially due to the possibility of integration of multiple data sources, such as population characteristics and location of impacts sources, and the representation of data in map format in order to visualize the spatial distribution patterns of potential impacts.

This paper argues that it is possible to recognize situations of environmental inequity related to water access of acceptable quality for human beings and identify the population more exposed to the risks of water shortage, especially during water scarcity crises. The recognition and identification of this situation, through a prior and mature environmental equity analysis, may reduce and even avoid water conflicts, as well as improve and enlarge Water Resources Management (WRM), which sometimes can be blinded by data and indicators that do not reveal the reality.

\section{ENVIRONMENTAL EQUITY AND WATER RESOURCES}

The perception that environmental hazards and risks are unevenly distributed is not so obvious, especially for people who are far from the problem itself. While most empirical investigations of environmental equity have focused on the geography of industrial pollution or the locations of landfills and waste sites and historical process in urban areas (e.g. Pham et al. 2012), few investigations have considered the unequal access to adequate quantities of acceptable quality water for sustainable livelihood, human well-being and socio-economic development. 
The water-related environmental equity studies are necessary to address the issues of equitable water access and water scarcity, considering the different water uses and demands (urban, agricultural and industrial) and a water of lower quantity and quality. Some of these studies mainly consider the contributions of historical and political ecology aspects (e.g. Cai 2008, Perreault et al. 2012), suggesting that there is much more work to be done.

The perspective of waterscape has been adopted in the analysis of water-related environmental equity studies. This term is emerging from water governance reviews and studies and links water and social power relations, despite other different meanings. Waterscape is defined in the environmental equity literature as "the ways in which flows of water, power and capital converge to produce uneven socio-ecological arrangements over space and time" (Budds and Hinojosa 2012).

\section{CASE STUDY}

An unequal access to adequate quantities of water for human consumption in a drought-prone area is analysed in this paper. This condition becomes evident in water shortage periods, when a portion of the population runs out of water, a real situation of environmental inequity.

Campina Grande is the major city in inner Paraíba State, Brazil, and an economic and educational pole, situated in the semi-arid and drought-prone region of Brazilian NE. It is located at $7^{\circ} 13^{\prime} 11^{\prime \prime} \mathrm{S}$ and $35^{\circ} 52^{\prime} 31^{\prime \prime} \mathrm{W}$ with altitude range from 337 to $665 \mathrm{~m}$ a.m.s.l. The urban area is of 96 $\mathrm{km}^{2}$ with a population of 385213 inhabitants according to the last (2010) National Census (IBGE 2012). The urban population represents $95 \%$ of the total.

The current water supply system for Campina Grande and for more 26 smaller neighbouring cities is based on the Epitácio Pessoa Reservoir, also known as Boqueirão Reservoir. It is also the water source for irrigated agricultural lands and for fishery. It has a gross capacity of $411 \mathrm{hm}^{3}$. The reservoir contributing basin lies in the driest region of Brazil, with high natural climate variability, with the rainy season concentrated between February and May. Evaporation rates are very high and the rainfall forecasting system does not supply reliable information for more than one year ahead (Galvão et al., 2001). Boqueirão and its water users can be considered a typical waterscape.

The Boqueirão Reservoir had the lowest water storage level and worst water quality of its lifetime, in the 1997-1999 period (Galvão et al. 2001, Rêgo et al. 2001). At that time, a water rationing scheme was adopted for urban consumption from 1998 until 2000: Campina Grande was divided into two areas. In November 1998, water supply was off for one of those areas, each time, every $24 \mathrm{~h}$. In September 1999, it was necessary to increase that interval for $48 \mathrm{~h}$. Besides, other related actions were taken, such as suspension of withdrawal for irrigation and interruption of discharge flow for river downstream. In November 1999 only 15\% of its capacity was available; salt concentration in water made it no longer drinkable, and some urban areas remained even four days without water supply. The reservoir came to that point because of a complete absence of water management. In April 2000 the rationing was suspended, after the water storage level increased during the rainy season.

During the 1997-1999 water rationing period, the whole population of Campina Grande was affected by water scarcity but not in the same way: medium and high-income people had stored water in their household tanks and consumed bottled mineral water and/or desalinated water, while the low-income people had stored water in pots and pans (Rêgo et al. 2001).

A current drought period that started in 2012 indicates a possible new cycle of water scarcity, which may lead to the collapse of Boqueirão Reservoir in January 2015, considering current water consumptions rates and the possibility of keeping a drought condition in 2014. In order to delay the collapse of the system, water rationing should start in July 2014. Similar problems might be expected under climate change in the next decades. Nevertheless, the results published by the Brazilian National Sanitation Information System (SNIS 2010), based on urban scale, indicate that $99.49 \%$ of Campina Grande's population is served with good quality water.

This case can be considered representative of other cities around the world (e.g. Potter et. al. 2010). One issue which may arise is whether the water access inequity can be rapidly estimated for 
several cities at regional or national scales from easily available census or survey data. This information could be very valuable for developing prevention measures to reduce vulnerabilities and thus increase equity. In the following sections we address this issue for the case of Campina Grande, presenting a simple set of indicators that can be useful for this purpose.

\section{INDICATORS OF WATER SUPPLY INEQUITY}

The indicators applied to identify environmental inequity related to water access in Campina Grande were developed based on the following assumptions:

(a) Income - Low-income people were considered more vulnerable to the risk of water shortage compared to middle and high-income people. During the 1997-1999 crisis, higher income people could afford to buy mineral and/or desalinated water and storage tanks (which served as buffers during the supply interruptions), while low-income people were at a disadvantage as they could not afford to buy any of them (Rêgo et al. 2001). It is the economic criterion.

(b) Slums - According to the Brazilian Census database (IBGE 2012), slum is a set consisting of at least 51 households, under-served by most of the essential public services, occupying or having occupied illegal land or land owned by others (public or private) for the last 10 years and being arranged generally in a disorderly and dense manner. Because of their precarious conditions, they are considered more vulnerable to the risk of water shortage compared to other census tracts. It is the social criterion, based on minimum living conditions.

(c) Household location relative to those of water distribution reservoirs - the higher the households elevations are in relation to the water distribution reservoirs and the greater the distances between households and those reservoirs, the higher the risk of water shortage (Cordão et al. 2013). It is considered the hydraulic criterion, which may worsen the water shortage condition.

(d) Housing units in vertical condominiums (condos) - They have an inherent feature, in Brazil, that is the presence of water reservoir(s) or $\operatorname{tank}(\mathrm{s})$ inside the building, which guarantee a water storage capacity not necessarily considered in the design of other households types. They mitigate the impact of supply interruptions.

Economic and social indicators were selected because they support major governmental decisions and define institutional, political and economic structures. The indicators "income", "slums" and "housing units in vertical condominiums" were collected from variables of the 2010 Brazilian Census database available in the Web (IBGE 2012). The "income" grading was divided into four economic classes (up to 1 minimum wage, from 1 to 5 , from 5 to 10 , and over 10 minimum wages), as shown in Fig. 1(a), according to the Brazilian categorization system. The "slums" indicator was based on the location of the slums in the urban area, as shown in Fig. 1(b), and two classes were considered: slums and others. Data on elevation and distance to water reservoirs for the hydraulic criterion were obtained from previous studies about Campina Grande's Water Supply System (Cordão et al. 2013).

Other indicators included in the Brazilian National Sanitation Information System (SNIS) might be considered to identify environmental inequity, such as water production, water consumption, interruptions in water supply (quantity and duration) and water quality, but they have not been measured systematically for Campina Grande's urban area with intra-urban resolution.

\section{ESTIMATION OF WATER SUPPLY INEQUITY}

GIS technology was used for manipulating census data (monthly income, location of slums and number of housing units in vertical condominiums) and physical data (elevation and distance from water supply reservoirs) and for representing them, as well as the logical relationships to integrate the inequity indicators.

The vulnerability based on economic and social criteria considered the following hypothesis: census tracts with "very high vulnerability" have either income up to 1 minimum wage (Fig. 1(a)) or the presence of slums (Fig. 1(b)); census tracts with "high vulnerability" present income from 1 
to 5 minimum wage (Fig. 1(a)); census tracts with income over five minimum wage present "no vulnerability". Data were overlaid and the vulnerability map based on economic and social criteria is shown in Fig. 2.

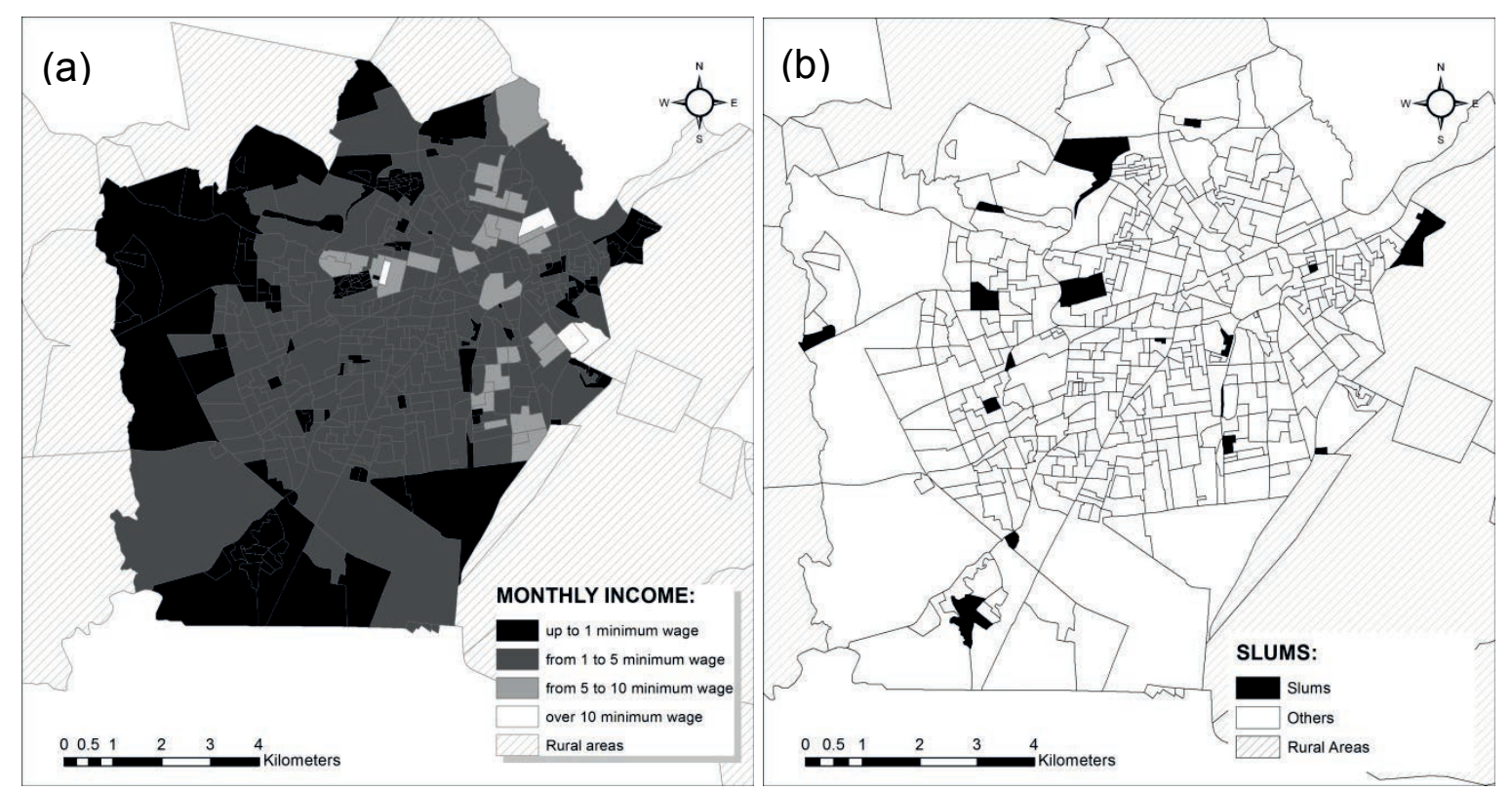

Fig. 1 (a) Monthly income per census tract and (b) Slums locations of Campina Grande's urban area.

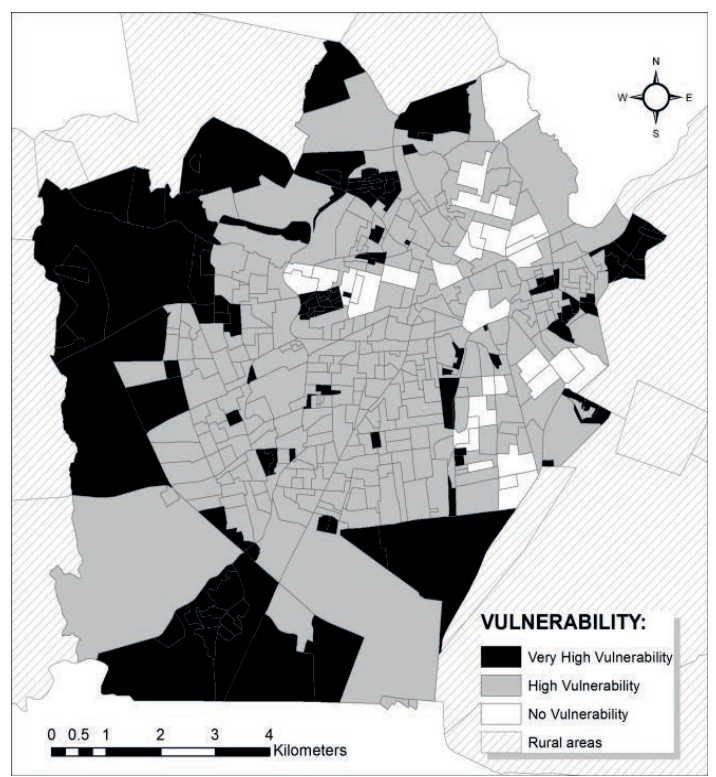

Fig. 2 Vulnerability map based on economic and social criteria.

The supply risk map based on hydraulic criterion, shown in Fig. 3, considered the hypothesis that "highest elevation AND most distant from a reservoir" entails the hardest condition for water supply. The variables elevation data and distance to water reservoirs were integrated through a fuzzy overlay using a linear function: the minimum elevation value was set to 0 and the maximum value was set to 1 , and the minimum distance to water reservoir was set to 0 and the maximum was set to 1. The results were classified in three classes: low, medium and high. Based on the hydraulic criterion, the vulnerability presented in Fig. 2 may be increased according to the hypothesis that "high vulnerability AND high risk" leads to "very high vulnerability", as shown in Fig. 4. 


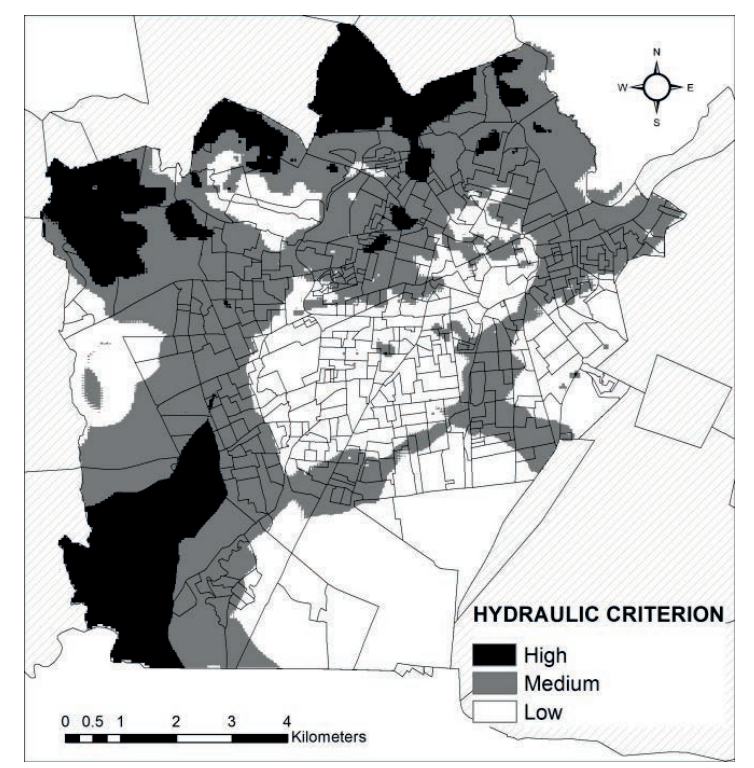

Fig. 3 Supply risk based on hydraulic criterion.

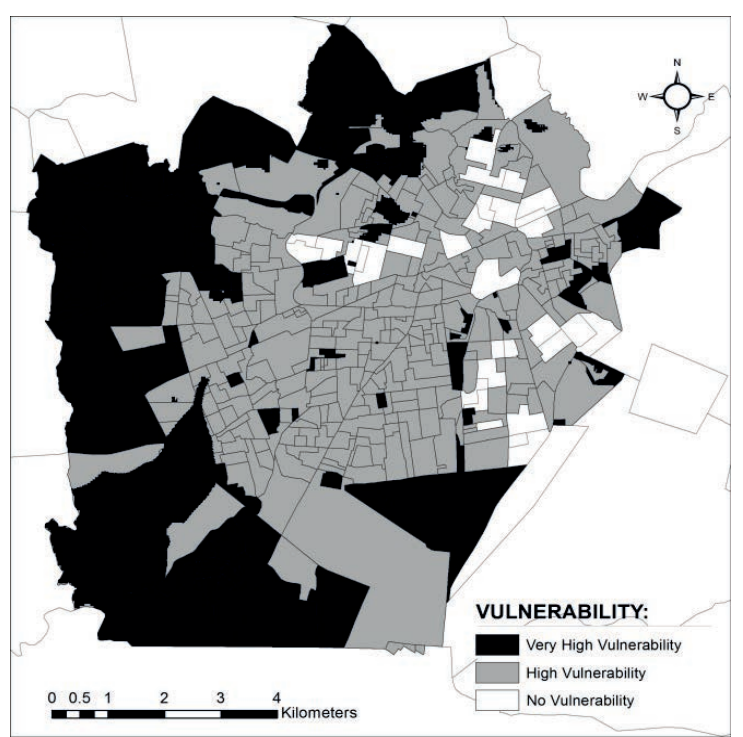

Fig. 4 Vulnerability (increased by hydraulic criterion).

On the other hand, supply interruptions were mitigated due to the presence of water reservoir(s) inside the housing units in vertical condominiums. In order to consider it, the percentage of housing units in vertical condominiums per census tract were classified in three different classes - up to $25 \%$; from 25 to 50\%; and over 50\%, as shown in Fig. 5. Those tracts with over 50\% were considered the best condition for water supply, decreasing their vulnerability, as in Fig. 4, to "No Vulnerability" status, as shown in Fig. 6.

The environmental inequity in Campina Grande, generated by water scarcity in past crises, was caused by natural and institutional processes: the natural climate variability and the absence of water management in Boqueirão Reservoir. It is a typical waterscape scenario where water and socialpower relations are not measured nor represented. On the imminence of a new crisis, it is urgent to consider the permanent and continuous representation of these indicators as well as the inclusion of other ones at intra-urban scale, that already exist but are not informed (SNIS indicators), in order to prevent conflicts and reduce environmental inequities in Campina Grande. On the long term, periodic diagnoses should guide plans and adjustments to reduce vulnerabilities. 


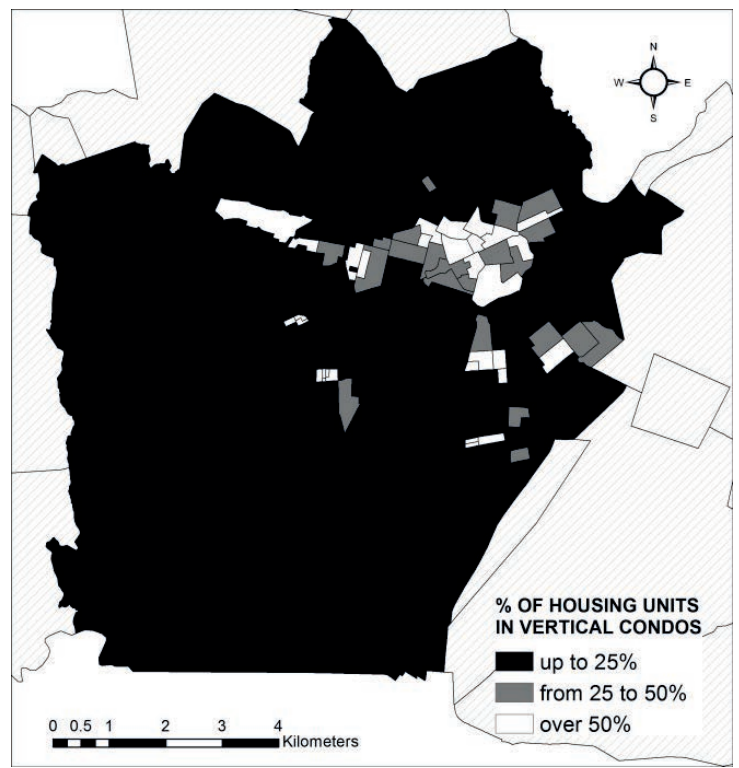

Fig. 5 Housing units in vertical condominiums.

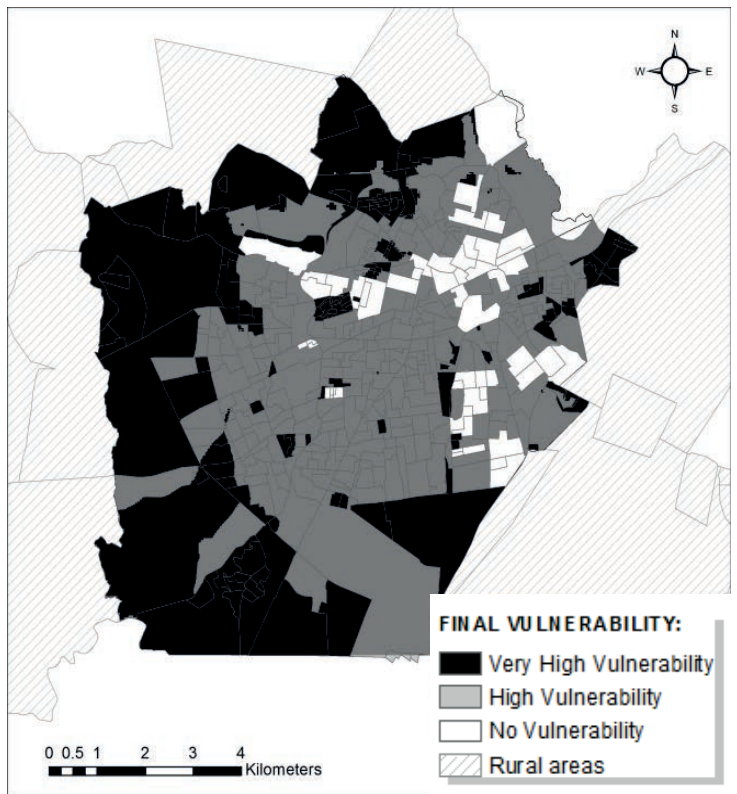

Fig. 6 Final vulnerability map.

\section{CONCLUSIONS}

The environmental equity analysis related to water access is a new perspective, based on the emerging waterscape concept. In this new concept water-related instances of inequities may come to be seen and considered by governments, society and institutions. A prior and mature environmental equity analysis can potentially reduce and even avoid water conflicts.

The reports from the 1997-1999 water scarcity crisis in Campina Grande, Brazil, told a history of an unequal availability of acceptable quantities of good quality water for human consumption. The impacts of the water rationing are different for people according to their economic and social situation, the location and type of their housing, among other factors. Indicators representing those aspects were developed and integrated to identify water access inequity in this case, as an additional criterion for water resources management. It is thus possible to use widely available information to estimate inequity and potentially impacted social groups. 
Acknowledgements The research leading to this paper had the support from Brazilian Agencies CAPES, CNPq and FINEP.

\section{REFERENCES}

Budds, J. and Hinojosa, L. (2012) Restructuring and rescaling water governance in mining contexts: the co-production of waterscapes in Peru. Water Alternatives 5(1), 119-137.

Cai, X. (2008) Water stress, water transfer and social equity in Northern China - implications for policy reforms. Journal of Environmental Management 87(1), 14-25. doi:10.1016/j.jenvman.2006.12.046.

Carr, G. (1996) Environmental equity: does it play a role in WTE siting? Journal of Hazardous Materials 47, $303-312$.

Cordão, M. J. de S., Rufino, I. A. A. and Araújo, E. L. de (2013) Geotechnologies applied to management of urban water supply systems: a methodologic proposal. Engenharia Sanitária e Ambiental 18(3), 263-274 (in Portuguese).

EPA (n.d.) Environmental justice. Retrieved September 25, 2013, from http://www.epa.gov/environmentaljustice/

Galvão, C. O., et al. (2001) Sustainability characterization and modelling of water supply management practices. In: Regional Management of Water Resources (IAHS Publication nr 268), pp. 81-88. Maastricht.

Holifield, R. (2001) Defining environmental justice and environmental racism. Urban Geography 22(1), 78-90. doi:10.2747/0272-3638.22.1.78.

IBGE (2012) Censo 2010. Retrieved October 10, 2013, from http://censo2010.ibge.gov.br/

Perreault, T., Wraight, S. and Perreault, M. (2012) Environmental injustice in the Onondaga Lake waterscape, New York State, USA. Water Alternatives 5(2), 485-506.

Pham, T.-T.-H., et al. (2012) Spatial distribution of vegetation in Montreal: an uneven distribution or environmental inequity? Landscape and Urban Planning 107, 214-224.

Potter, R. B., Darmame, K. and Nortcliff, S. (2010) Issues of water supply and contemporary urban society: the case of Greater Amman, Jordan. Philosophical Transactions of the Royal Society A 368, 5299-5313.

Rêgo, J. C., et al. (2001) Society participation in 1998-2000 crisis of Campina Grande's water supply. In: IV Diálogo Interamericano de Gerenciamento de Águas. Foz do Iguaçu (in Portuguese).

SNIS (2010) National Sanitation Information System. Brasilia. 